\title{
REVIEW AND VERIFICATION OF THE PSYCHOMETRIC PROPERTIES OF THE MOOD INSTABILITY DIMENSION OF THE DIMENSIONAL CLINICAL PERSONALITY INVENTORY
}

\author{
Prof. Dr. Lucas De Francisco Carvalho ${ }^{* 1}$, Catarina Possenti Sette ${ }^{2}$ \\ ${ }^{1}$ Universidade São Francisco, Itatiba, SP - ${ }^{2}$ Universidade São Francisco, Itatiba, SP
}

Recibido, agosto 17/2014

Concepto de evaluación, junio 10/2015

Aceptado, junio 30/2015

\begin{abstract}
Referencia: Carvalho, L. F. \& Sette, C. P. (2015). Review and verification of the psychometric properties of the mood instability dimension of the Dimensional Clinical Personality Inventory. Acta Colombiana de Psicología, 18 (2), 115-127. DOI: 10.14718/ACP.2015.18.2.10
\end{abstract}

\begin{abstract}
The present study aimed to review the Mood Instability dimension of the Dimensional Clinical Personality Inventory (DCPI) and to examine its psychometric properties. To this end, new items were developed that were applied to 230 subjects, aged between 18 and 63 years $(M=23.0, S D=9.44)$, with a majority of females $(76.4 \%)$. All participants answered the DCPI, the Brazilian version of the NEO Personality Inventory-Revised and the Brazilian version of the Personality Inventory for DSM-5 (PID-5). As a result, 306 new items were developed based on four sources of reference in the area and selected by means of content analysis and 27 items to compose the final version of the dimension to be applied. After data collection and statistical analysis, the reviewed dimension was composed of three factors plus a total score. The internal consistency coefficients were adequate and equal to .85 for the final set of 16 items, with a variation range between .78 and .81 per factor. Moreover, the expected intracorrelations were found, as well as consistent correlations with the instruments used. Data allow inferring validity evidence for the scale reviewed, as well as demonstrating satisfactory internal consistency.

Key words: personality disorders, psychometrics, personality traits.
\end{abstract}

\section{REVISIÓN Y VERIFICACIÓN DE LAS PROPIEDADES PSICOMÉTRICAS DE LA DIMENSIÓN INESTABILIDAD DEL ESTADO DE ÁNIMO DEL INVENTARIO DIMENSIONAL CLÍNICO DE LA PERSONALIDAD}

\author{
Resumen
}

\begin{abstract}
El presente estudio tuvo como objetivo examinar la dimensión Inestabilidad del Humor del Inventario Dimensional Clínico de la Personalidad (IDCP), y la investigación de sus propiedades psicométricas. Para ello se desarrollaron nuevos ítems que fueron aplicados a 230 participantes, con edades comprendidas entre 18 y 63 años $(M=23,0, D P=9,44)$, la mayoría de sexo femenino (76,4\%). Todos los participantes respondieron el IDCP, la versión brasileña de la versión revisada del Inventario de Personalidad NEO, y la versión brasileña del Inventario de Personalidad para el DSM-5 (PID-5). Como resultado, 306 nuevos ítems fueron desarrollados con base en cuatro fuentes de referencia, y seleccionados mediante análisis de contenido, y 27 ítems que conformaron la versión final para la aplicación de la dimensión. Después de recoger los datos y de realizar el análisis estadístico, la dimensión analizada constaba de tres factores, además de una puntuación total. Los coeficientes de consistencia interna fueron adecuados e iguales a 0,85 para el conjunto final de 16 ítems con un rango de variación entre 0,78 y 0,81 por cada factor. De otra parte, se encontraron las intracorrelaciones esperadas, así como correlaciones coherentes con los instrumentos utilizados. Los datos permiten inferir evidencias de validez de la escala revisada, así como una demostración satisfactoria de la consistencia interna.

Palabras clave: trastornos de la personalidad, psicometría, rasgos de personalidad.
\end{abstract}

\footnotetext{
* Universidade São Francisco, Rua Alexandre Rodrigues Barbosa, 45 CEP 13251-900, Itatiba, São Paulo, Brasil.lucas@labape.com.br; Telefone: +55 (11) 4534-8053 Fomento: FAPESP; CNPq; CAPES.
} 


\title{
REVISÂO E VERIFICAÇÃO DAS PROPRIEDADES PSICOMÉTRICAS DA DIMENSÁO INSTABILIDADE DE HUMOR DO INVENTÁRIO DIMENSIONAL CLIINICO DA PERSONALIDADE
}

\begin{abstract}
Resumo
O presente estudo teve como objetivo revisar a dimensão Instabilidade de Humor do Inventário Dimensional Clínico da Personalidade (IDCP), investigando suas propriedades psicométricasPara tanto, novos itens foram desenvolvidos, para então serem aplicados. Participaram 230 sujeitos, com idade variando entre 18 e 63 anos $(M=23,0 ; D P=9,44)$, sendo a maior parte do sexo feminino (76,4\%). Todos os participantes responderam o IDCP, a versão brasileira do Inventário de Personalidade NEOPI Revisado e a versão brasileira do Personality Inventory for DSM-5 (PID-5). Como resultado, foram desenvolvidos 306 novos itens com base em quatro fontes de referencia na área e selecionados, por meio de análise de conteúdo, 27 para compor a versão final de aplicação da dimensão. Após a coleta de dados e análises estatísticas, a dimensão revisada ficou composta por três fatores, além de um escore total. Os coeficientes de consistência interna mostraram-se adequados sendo igual a 0,85 para o conjunto final de 16 itens e variando de 0,78 e 0,81 por fator. Além disso, foram encontradas intracorrelações esperadas, bem como correlações coerentes com os instrumentos aplicados. Os dados permitem inferir evidências de validade para a dimensão revisada, além de demonstrar índices satisfatórios de consistência interna.

Palavras-Chave: transtornos de personalidade, psicometria, traços de personalidade.
\end{abstract}

\section{INTRODUCTION}

In the present study, a literature research with the descriptor personality in the Scielo database found 481 national publications, while the Science Direct International database shows 9227 publications with the same construct (using the descriptor in the English language). Despite the evident discrepancy between the number of national and international publications, it is clear that this is one of the most studied constructs in psychology (John, Robins \& Pervin, 2008). This research has been conducted within this framework, presenting the revision of one of the dimensions of the DCPI (Dimensional Clinical Personality Inventory), one of the few Brazilian instruments designed to assess personality characteristics specifically in the more pathological ranges of the construct.

In general, personality is understood as a pattern of interrelated, persistent characteristics that are often not conscious, almost automatic and displayed in the individual's typical environments. It is also understood on a continuum, i.e., on the one hand, as successful patterns to meet daily demands, and on the other, as maladaptive patterns that may lead to difficult socialization in different environments, with obvious damage in many areas of life over time (Millon, Millon, Meagher, Grossman \& Ramanath, 2004).

A more pathological personality functioning can be defined according to three relevant characteristics: adaptive inflexibility, vicious circle, and tenuous stability (Millon, 2011). Adaptive inflexibility refers to the difficulty in relating to others, dealing with stress, and using few and ineffective strategies to achieve goals. The vicious circle is related to behaviors that persist and accentuate pre-existing difficulties in the individual, and tenuous stability is related to a lower resilience against psycho-stressing situations.

In certain cases, the pathological personality functioning can be characterized as a personality disorder (PD), considered as demonstrations of different patterns in which the personality works in a maladaptive way towards the environment, resulting in substantial losses in people's lives (Millon, 1993; Widiger \& Trull, 2007; Millon, Grossman $\&$ Tringone, 2010). This definition corroborates the publications that supported the fifth version of the Diagnostic and Statistical Manual of Mental Disorders ([DSM-5];APA, 2013), since according to Skodol et al. (2011), an individual is diagnosed with a PD when he or she presents significant losses related to the self, which includes dimensions such as identity and self-direction, and in interpersonal functioning, issues associated with empathy and intimacy.

There are several proposals for the evaluation of the typical features of PDs in the literature, including Theodore Millon's theory, which aims to integrate conceptual bases, assessment and intervention of disorders. It is considered a model that provides robust theoretical framework and tools to measure these constructs (for further theoretical data see Millon \& Davis, 1996; Millon et al, 2004; Millon \& Grossman, 2007a; 2007b; Millon et al., 2010; Millon, 2011), and presents empirical support evidenced on the Millon Clinical Multiaxial Inventory ([MCMI]; Hatch, 2004; Millon \& Davis, 1996, 1997; Millon \& Davis, 1997; Strack \& Millon, 2007). Millon's proposal fits in what is understood as appropriate in relation to a comprehensive approach to personality and its disorders, as it considers personality at its various levels and dimensions (Loureiro, 2000). 
Based on the proposal by Millon and on axis II of the DSM-IV-TR (APA, 2003) and with empirical support on the dimensional design, Carvalho and Primi (2015, in press) developed the Dimensional Clinical Personality Inventory (DCPI). It is a self-report instrument for assessing pathological aspects of personality, consisting of 163 items distributed in 12 dimensions, which are: Dependency, Aggressiveness, Mood instability, Eccentricity, Attention Seeking, Distrust, Grandiosity, Isolation, Criticism Avoidance, Self-sacrifice, Conscientiousness, and Impulsiveness. Each dimension is more related to the pathological personality styles proposed by Millon (2011).

Carvalho and Primi (2015, in press) and Carvalho, Primi and Stone (2014) investigated the psychometric properties of the DCPI, which presented appropriate data in relation to reliability indices $(\alpha>0.70)$, based on Nunnally (1978), and evidence of validity based on the internal structure (exploratory and confirmatory factor analysis and model scale rating) and in relation to external variables (NEO Personality Inventory Revised and psychiatric diagnosis). In the latter case, the correlations were in accordance with what was expected conceptually. It is noteworthy, however, that despite the suitability of the instrument's psychometric properties, Carvalho and Primi (2015) suggested some recommendations to improve the instrument's dimensions.

Among the recommendations, the dimensions that needed more specific reviews were emphasized: Conscientiousness and Attention Seeking, based on the high occurrence of endorsement in these dimensions, i.e., the items were more likely to assess healthy and non-pathological characteristics. Moreover, the Conscientiousness dimension presented an internal consistency (Cronbach's alpha) equal to 0.69 , which was therefore, lower than 0.70 (cut-off point adopted).

Carvalho, Souza and Primi (2014), reviewed and verified the psychometric properties of the Conscientiousness dimension, and Carvalho, Sette, Captain and Primi (2014) reviewed and verified the psychometric properties of the Attention Seeking dimension. In both studies, a procedure divided in two steps was adopted: the development of new items for the revised dimension (step 1), followed by the verification of the psychometric properties of the revised dimension (step 2). In the first step, relevant models in the area focused on pathological personality characteristics were verified, namely, the fifth edition of the DSM (APA, 2013); the dimensions of the Personality Inventory for DSM-5 ([DSM-5]; Krueger, Derringer, Markon, Watson \& Skodol, 2011); the dimensions assessed by the ShedlerWesten Assessment Procedure ([SWAP]; Westen \& Shedler, 1999); and the dimensions proposed by Anna Clark (1990), which are the bases for the Schedule for Nonadaptive Personality (SNAP). Based on these sources, a set of items was developed and those considered to be most suitable were selected for implementation along with the original items of the scale.

In the second stage, the DCPI with the revised dimension was applied together with other instruments relevant to the focus dimension of each of the studies. Based on the administration of the instruments, analyses were conducted to examine the internal structure, reliability coefficients for internal consistency, and relations with external variables for the specific dimension. The present study is part of the collection of studies aimed at improving the DCPI dimensions, using the procedures of the aforementioned studies (Carvalho et al., 2014; Carvalho et al., 2014).

In this study the revised dimension is Mood instability, which is closely related to the borderline PD characteristics. In the DCPI this dimension refers to the tendency to exhibit sad and irritable mood, but also to oscillations in mood and beliefs which lead to impulsive and extreme reactions, often generating guilt, and which may result in suicide (Carvalho $\&$ Primi, 2015; in press). The main bases for the revision of the Mood Instability dimension were the constructs found in the literature, which are clearly related to its definition, and the typical features of the borderline PD, a functioning that presents a close relationship with the Mood Instability dimension (Carvalho \& Primi, in press).

According to the DSM-5 section 2 (APA, 2013), for an individual to be diagnosed with borderline PD, at least five of the nine criteria must be met. The criteria include aspects related to impulsivity, fear of abandonment and rejection, excessive dependency, intense interpersonal relationship patterns, identity disturbance, recurrent suicidal behavior, affective instability, chronic feelings of emptiness, intense anger, and paranoid ideation. Other features resulting from this disorder, which are corroborated by the literature (Leichsenring, Leibing, Kruse, New \& Leweke, 2011), are the presence of anxiety comprising intense feelings of nervousness or panic, often in reaction to interpersonal tensions; tendency to worry about past unpleasant experiences and negative future possibilities; feelings of fear, apprehension or threat by uncertainty. In addition, frequent feelings of sadness, pessimism about the future and suicidal thoughts are seen in people diagnosed with borderline PD (APA, 2013).

Complementing these data, in studies conducted to understand the pathological functioning patterns, including the borderline personality disorder, Mullins-Sweatt et al. (2012) showed a significant relationship between this personality functioning with aspects covered by the Neuroticism dimension of the Big Five-Factor model (including irritability, vulnerability, depressiveness, anxiety, etc.), whose definition is similar to that of the Mood Instability 
dimension of the DCPI. In addition, these authors suggested that the borderline PD involves low confidence and compliance, typical characteristics of the inferior pole of the Extraversion dimension and low competence, of the Conscientiousness dimension. Corroborating these data, Samuel and Widiger (2004) also showed positive relationships of the borderline PD with Neuroticism and negative relationships with Extraversion, Agreeableness and Conscientiousness. These four dimensions (Neuroticism, Extraversion, Agreeableness and Conscientiousness) were assessed in the studies cited by the NEO-PI-R.

More specifically, also based on the NEO-PI-R, the literature presents the relationship of the borderline PD with 11 personality traits (Mullins-Sweatt et al., 2012), some of which are positive and others are negative. The traits with positive relationships are: anxiety, hostility with anger, depressiveness, conscientiousness, impulsiveness, vulnerability and fantasy; and with negative relationships: trust, straightforwardness, compliance, and deliberation.

From an empirical standpoint, a study was conducted by Abela (2013) in Brazil to examine the personality profile of patients diagnosed with PD. Among other results verified using the DCPI, the author compared the profile of the borderline group $(\mathrm{N}=30)$ with those of other participants of the sample with diagnosis of PD who did not present the diagnosis of borderline $\mathrm{PD}(\mathrm{N}=57)$. The results indicate that the profile of the borderline group showed higher intensity in the dimensions Mood Instability, Eccentricity, Isolation, and Criticism Avoidance and moderate intensity in the Dependence dimension. Despite the moderate severity presented in the Dependency dimension, the subjects diagnosed with borderline PD proved to be nearly as incapable to rely on themselves to make decisions as the rest of the study participants, suggesting that this is not a feature that distinguishes the borderline disorder from other disorders present in the sample. The Criticism Avoidance factor was also high in the non-borderline group, but it was even higher in the borderline group. The dimensions that most differentiate the borderline group from the non-borderline were: Mood Instability, Impulsivity, Grandiosity, Eccentricity, Aggressiveness and Isolation. The group also showed higher values for Distrust and Attention Seeking than the non-borderline group.

Accordingly, the dimensions of the DCPI demonstrate an ability to distinguish between personality profiles according to external criteria (e.g., psychiatric diagnosis). However, as already highlighted, Carvalho and Primi (2015) suggest the improvement of the instrument dimensions, considering the reliability indices and the representativeness of the construct measured by dimensions, besides the need to update the instrument based on relevant sources present in the literature. Thus, the authors indicated the need to expand the representativeness of the constructs assessed by the dimension, considering literature findings different from those already used in the development of the DCPI. This research aims to review the Mood Instability dimension as well as to verify the psychometric properties of the new version of the dimension. The study also sought to establish distinguishable profiles based on factors composing the revised dimension, which should enable to differentiate among subjects with similar total scores on the dimension but who would still differentiate in the latent construct evaluated.

\section{METHOD}

Given the objectives of this research, the method has been subdivided: the first part (Phase I) presents the procedures for the review of the Mood Instability dimensions, and the second part (Phase II) presents the information on the empirical verification of the psychometric properties of the dimension.

Procedures for the review of the Mood Instability dimension (Phase I)

This phase was fragmented into six stages. The first one was characterized by the literature review to verify the characteristics related to the Mood Instability construct and the borderline PD, as this is the PD most typically related to the underlying construct of the dimension (Millon, 2011). The survey focused on publications based on four main sources: the DSM-5 (APA, 2013); the dimensions of the PID-5 components (Krueger et al, 2011.); the dimensions evaluated by the SWAP (Westen \& Shedler, 1999); and the dimensions proposed by Anna Clark (1990) which provide the basis for the Schedule for Nonadaptive Personality (SNAP).

In the second stage, the constructs and dimensions related to Mood Instability and borderline PD were selected according to the sources cited. Then an electronic spreadsheet was prepared with the dimensions and respective original characteristics of each model, in English, where the authors translated independently, reaching a final and consensual version of the translation. The third stage relates to the operation of selected constructs, i.e., the development of new items for the Mood Instability dimension according to the selected constructs and dimensions of the above-mentioned models. In the next, or fourth stage, the researchers separately selected the items deemed most appropriate. Then, the selections were compared and a consensus was reached regarding the selected items. 
In the fifth stage the items were grouped into categories according to their content. Also at this stage, the items of the original version of the IDCP were also allocated to the categories created. Thus, the original items and those developed could be compared regarding the peculiar content assessed. At that this stage, we sought to exclude items (new) redundant to the originals. Finally, in the sixth stage, the new items were chosen to compose the revised and final version for the application of the Mood Instability Humor dimension, based on the comparison conducted earlier.

Verification of the psychometric properties of the Mood Instability dimension (Phase II)

In this phase the psychometric properties of the revised Mood Instability dimension were verified, ie, reliability and validity evidences.

\section{Participants}

Survey participants were 230 subjects, aged between 18 and 63 years $(\mathrm{M}=23.0, \mathrm{SD}=9.44), 176$ females $(76.52 \%)$ and 54 males $(23.47 \%)$. Most of them had incomplete higher education $(52.6 \%)$, followed by university graduates $(17.8 \%)$, and were accessed by convenience at a private university in the countryside of the state of São Paulo. Regarding the psychiatric treatment history and/or use of psychotropic medications, $9.5 \%$ of the subjects answered that they had already been or were under psychiatric treatment and only $2.2 \%$ of participants had used medication. As for psychological treatment, $41.3 \%$ of them reported having undergone or were still under psychotherapeutic monitoring. Data collected on the sample (e.g., being under psychiatric treatment or use of psychotropic medication) suggested variability regarding the levels presented in the personality characteristics assessed, indicating the suitability of the sample for this study.

\section{Instruments}

1. Dimensional Clinical Personality Inventory (DCPI). It is an instrument developed by Carvalho and Primi (2015), based on Millon's theory and the diagnostic criteria of the categories presented on axis II of the DSM-IV-TR (APA, 2003). The instrument consists of 12 dimensions of personality, whose items are arranged in a 4-point Likert-like scale, where 1 corresponds to "it has nothing to do with me" and 4 "everything to do with me". The average time for administration of the instrument is 25 minutes.

Once the instrument is administered, profiles are obtained based on the dimensions, so that high scores suggest characteristics tending to a more pathological personality functioning (Primi \& Carvalho, 2015; in press). As already reported, the psychometric properties of the DCPI were verified in previous studies (Carvalho \& Primi, 2015; in press; Carvalho, Stone \& Primi, 2014) and, in general, suggest the suitability of the test. In this study, specifically, a version of the DCPI was administered which included the Mood Instability dimension revised.

2. Revised Neo Personality Inventory (NEO-PI-R) in the translated version (Costa Jr. \& McCrae, 2009). It is a selfreport inventory, composed of 240 items, whose objective is the psychological assessment of the adult personality in five dimensions: Neuroticism, Extraversion, Openness to Experience, Agreeableness, and Conscientiousness. The instrument must be answered on a 5-point Likert-like scale, ranging from "strongly disagree" (1) to "strongly agree" (5). The administration time is approximately 30 minutes. The manual of the Brazilian version of the instrument presents several studies showing evidence of validity and good reliability (Costa Jr. \& McCrae, 2009). For this study only the dimensions Agreeableness and Neuroticism were considered, taking into account that (Costa Jr. \& McCrae, 2009) Neuroticism is the only dimension of the five-factor model that assesses less healthy aspects, and Agreeableness is related to interpersonal difficulties, present in cases of pathological personality patterns and typical in cases of borderline functioning (APA, 2013).

3. The Personality Inventory for DSM-5 (PID-5; Krueger et al., 2011), in the version translated and adapted for Brazil, but not yet published. The instrument is a self-report inventory for assessing pathological characteristics of personality, consisting of 220 items representing 25 facets (grouped into five dimensions), which must be answered in a 4-point Likert-like scale (zero being equal to "false or very often false" and three equal to "very true or often true"). The PID-5 was developed to measure the criterion $\mathrm{B}$ of the proposal for evaluation of the PDs for the DSM-5. There were no national studies verifying the psychometric properties of the Brazilian version of the instrument, but Krueger et al. (2011) present data indicating the adequacy of the original version of the test. For this survey only the dimensions Anxiety, Depressiveness, Emotional Lability, Separation Insecurity, and Impulsivity were considered.

\section{Procedure}

This research was submitted to a Research Ethics Committee and after approval (CAAE 0144.0.142.000-07) data collection was conducted. The administration was completed collectively within classrooms, in one session for each class, requiring an average time of 1 hour and 15 minutes. According to demand and access, some applications took place individually in private establishments outside the University. First, the research objectives were explained 
and after subjects agreed to participate in the study, signed the Informed Consent Form and then responded to the survey instruments.

When data collection was completed, these were tabulated and statistical analysis was performed. The number of factors to be maintained based on the parallel analysis to polychoric variables was verified, using R software version 2.15.3 (Hayton, Allen \& Scarpello, 2004; Watkins, 2006). Then, a database was generated for the software version 6.12 MPlus to perform exploratory factor analysis to polychoric variables (E-SEM), and to obtain fit indices that indicate the suitability of the structure found based on the present sample, considered appropriate from 0.70 (Embretson 1996; Nunnally, 1978). For the E-SEM, the Geomin oblique rotation and Maximum Likelihood (ML) extraction method were used, considered suitable for polychoric variables. The factors of the constructs related to the Mood Instability dimension were correlated with the two dimensions of the NEO-PI-R and the five dimensions of PID-5.

\section{RESULTS}

In the following paragraphs the results of the study are presented. First, the data regarding the first phase, referring to the development of the six stages for the reformulation of the dimension the IDCP. Then the statistical analyzes to verify the psychometric properties of the new dimension, which includes investigating the internal structure of the set of items, its internal consistency, and its relationship with other variables.

Regarding the first stage, as mentioned above, proposals for DSM-5, 5-PID, SWAP and Clark were used since these are consistent with current models reported in the literature. Regarding the DSM-5, the diagnostic category typically related to this dimension is the borderline PD, and the dimensions considered in this study were identity, self-direction, empathy and intimacy. Of the 25 facets of PID-5 (instrument for the assessment of personality traits in accordance with the proposal of DSM-5), the facets Anxiety, Emotional lability, Depressiveness, Impulsivity and Separation Insecurity were used.

Regarding the SWAP, Shedler and Westen (2004) conducted a study that found 12 factors related to the pathological characteristics of personality, and among these factors, the emotional dysregulation factor refers to characteristics related to the dimension Mood Instability of the DCPI, since it deals with sentences related to unexpected and unpredictable changes of emotions; expression of emotions in exaggerated and theatrical way; inability to calm down when distressed; trend to become irrational when strong emotions are aroused; and tendency to be overly dependent, requiring approval and reassurance. Furthermore, in the model presented by Clark (1990) there are dimensions also related to this dimension, and to the borderline PD, such as: self-derogation, anger/aggression, anhedonia, dependence, impulsivity, self-centered exploration, suicidal tendency, and instability. Based on the selected constructs and dimensions, new items were created, with a total of 306 items developed, distributed according to the constructs, as it can be verified in Table 1 .

Table 1.

Set of items selected by consensus

\begin{tabular}{|c|c|c|c|}
\hline & \multicolumn{3}{|c|}{ Items } \\
\hline Construct & Created & Pre-selected & Selected \\
\hline Anxiety & 45 & 15 & 6 \\
\hline Emotional Liability & 35 & 7 & 0 \\
\hline Depressiveness & 70 & 18 & 7 \\
\hline Impulsiveness & 30 & 6 & 2 \\
\hline Insecurity of Separation & 25 & 4 & 3 \\
\hline Identity & 5 & 1 & 0 \\
\hline Self-direction & 5 & 2 & 1 \\
\hline Empathy & 6 & 1 & 0 \\
\hline Intimacy & 5 & 1 & 0 \\
\hline Emotional Dysregulation & 35 & 10 & 4 \\
\hline Self-derogation & 5 & 1 & 1 \\
\hline Anger/Aggression & 10 & 2 & 0 \\
\hline Anhedonia & 5 & 1 & 0 \\
\hline Dependency & 5 & 0 & 0 \\
\hline Impulsiveness & 5 & 1 & 1 \\
\hline Self-centered exploration & 5 & 1 & 0 \\
\hline Suicidal Tendency & 5 & 1 & 1 \\
\hline Instability & 5 & 2 & 1 \\
\hline Total & 306 & 74 & 27 \\
\hline
\end{tabular}

It can be also verified in Table 1 that in stage four, of the 306 items developed those regarded as the most appropriate according to their content were pre-selected reaching a consensus, resulting in a set of 74 items. Later, researchers, aiming to reduce the number of items, conducted a second selection, excluding items with redundant content and 
items with content deemed little pathological, and came to the end of the process with 27 items. The number of items developed ranged from 5 to 70 , pre-selected, from 0 to 18 , and selected items, from 0 to 7 , depending on the construct. Some dimensions did not have items selected in the final phase: emotional lability, identity, empathy, intimacy, anger/aggression, anhedonia, dependence and self-centered exploration, since the items were redundant in terms of content compared to the original ones, and the objective of this study was to seek items that would increase the representativeness of the construct in this dimension, i.e., with new content that had not been contemplated in the original version.

In the next stage, the 27 items were grouped into categories, arbitrarily created by researchers to verify the representativeness of the items elaborated and to group items of the original version of the scale. Table 2 shows the number of items according to the categories created.

Table 2.

Set of selected items by category

\begin{tabular}{lccc}
\hline \multicolumn{1}{c}{ Categories } & Originals & Pre-selected & Selected \\
\hline Concern & 1 & 15 & 6 \\
Depressiveness & 5 & 21 & 8 \\
Impulsiveness & 2 & 8 & 4 \\
Avoidance of separation & 0 & 5 & 4 \\
Disorientation & 2 & 4 & 2 \\
Emotional Intensity/ & 14 & 21 & 3 \\
Low resilience & 24 & 74 & 27 \\
TOTAL & & & \\
\hline
\end{tabular}

Table 2 consists of four columns; the first shows the created categories; the second, the number of original items in each category, and the third and fourth columns represent the number of pre-selected and selected items in the respective categories. It can be verified that there was a decrease between pre-selected and selected items for the application version of the revised scale. This decrease is a result of the comparison between the 74 selected items and the original items, which already included part of the contents of the pre-selected items. The contents presented on the table are called: Concern, referring to the difficulty to believe that things will work out, mainly because they have the belief that they made many mistakes in the past, tend to get nervous about the future and to be an anxious and concerned person; Depressiveness, grouping items related to thoughts of failure, suicide, guilt, sadness and difficulty in finding meaning in things; Impulsiveness, related to difficulties with self-control, acting on impulse without worrying about the result and short-lasting love relationships; Avoidance of separation, with beliefs related to the fear of being alone, and the need to do anything to prevent abandonment; Disorientation, referring to the feeling of having no clarity about themselves, feeling lost and difficulty deciding on things; Emotional intensity/low resilience, with items related to the need of help to control emotions and inability to control attitudes when carried away by emotions, often exaggerating.

Once the last stage was completed, the final version for application of the new Mood Instability dimension of the DCPI was obtained, composed of 27 original items and 27 new items, totaling 54 items. After collection, data were tabulated and statistical analysis was performed to investigate the adequacy of the variables by skewness and kurtosis, using a cut-off point between -2 and +2 . Of the total items, only nine presented a margin outside the established; however, only five of these items were maintained in the final structure of the revised dimension, two addressing suicide, two hopelessness, and one addressing self-mutilation. It is noteworthy that it was decided to keep these items given the relevance of their content to the revised dimension; the mean and standard deviation of the preserved items can be seen in Table 3. From the parallel analysis for polychoric variables up to four factors were obtained with significant eigenvalue not shown by chance. Next, factorial analysis with fit indices (E-SEM) was carried out investigating the solutions between 1 and 4 factors. First, the fit indices were analyzed, so that the three-factor solution was the one that most appropriately exchanged the fit and interpretability indices of the factors. The fit indices for this solution were $\mathrm{X} 2 / \mathrm{df}=2.26$; $\mathrm{RMSEA}=0.080 ; \mathrm{CFI}=0.693$; and $\mathrm{SMR}=0.059$. Considering the cut-off points (Hooper, Coughlan \& Mullen, 2008), the fit indices were good (SMR), acceptable (X2/df and RMSEA) and unsatisfactory (SMR). Despite the unsuitability of the indices, the structure as a whole was considered appropriate, by the other indices and the interpretative consistency, and therefore, the three-factor structure from the sample used in this study was maintained.

Table 3 presents the factor loadings found, the number of items held by factor, and the internal consistency rates (Cronbach's alpha). In addition, the items that remained in each of the factors are presented in bold. 
Table 3.

Exploratory factor analysis and internal consistency indices

\begin{tabular}{ccccc}
\hline & Vulnerability & Anxious Concern & Hopelessness & M (SD) \\
\hline 64 & 0.282 & 0.401 & 0.700 & $1.30(0.71)$ \\
95 & 0.575 & 0.409 & 0.042 & $2.10(0.90)$ \\
120 & 0.728 & 0.550 & -0.023 & $1.81(0.99)$ \\
151 & 0.702 & 0.461 & -0.014 & $1.92(1.0)$ \\
171 & 0.629 & 0.500 & 0.442 & $1.61(0.91)$ \\
173 & 0.720 & 0.526 & 0.352 & $1.53(0.83)$ \\
560 & 0.435 & 0.610 & -0.091 & $2.00(1.05)$ \\
561 & 0.428 & 0.560 & 0.123 & $1.64(0.83)$ \\
562 & 0.463 & 0.603 & 0.040 & $1.99(0.98)$ \\
565 & 0.368 & 0.584 & 0.014 & $2.50(1.16)$ \\
566 & 0.186 & 0.366 & 0.565 & $1.40(0.78)$ \\
567 & 0.292 & 0.342 & 0.761 & $1.17(0.54)$ \\
571 & 0.310 & 0.412 & 0.851 & $1.19(0.59)$ \\
579 & 0.265 & 0.484 & 0.128 & $1.72(0.99)$ \\
581 & 0.213 & 0.501 & 0.160 & $2.49(1.10)$ \\
586 & 0.465 & 0.323 & 0.251 & $1.28(0.70)$ \\
N. of items & 6 & 6 & 4 & \\
$\alpha$ & 0.81 & 0.78 & 0.81 & \\
\hline
\end{tabular}

Note. Only the items that were maintained are kept on the tables, facilitating the visualization of the data.

In Table 3 it is possible to verify that the final version of the dimension was composed of 16 items distributed into three factors, ranging from four to six items per factor, with explained variance of $56.31 \%$. It is important to highlight that it was sought to explicitly maintain a minimum number of items per factor, to avoid an extensive and comprehensive instrument, which would hamper its use by professionals. Therefore, four exclusion criteria were used: (a) the item harms or does not foster the internal consistency of the factor, (b) little interpretative consistency for maintaining the item on the factor, (c) significant loads on other factors (difference lower than 0.50 in inter-factor loads), and (d) content redundancy between items on the same factor. Thus, some items that had adequate factor loading did not remain. Regarding the internal consistency of the found factors, it was verified that all presented a coefficient higher than 0.70 , and the dimension obtained a ratio of 0.85 for the total set of 16 items.
Once the internal structure was defined, the factors of the dimension and their total scores were related and compared with the domains and facets of the other instruments, as well as with the original dimension. Table 4 presents the results of the correlations between the factors of the revised dimension, and the scores (original and revised).

The correlation between the factors of the Mood Instability dimension revised ranged from 0.26 to 0.49 . There is also a correlation of 0.87 between the total scores of the revised and the original dimensions, indicating high similarity between them, but it also reflects the changes in the new set of items. In addition, the original dimension obtained a higher correlation with Vulnerability and a lower correlation with Anxious Concern and Hopelessness. Table 5 presents the results of the correlations between the factors and the total score of the new dimension of Mood instability with the facets of the neuroticism dimension of the NEO-PI-R. 
Table 4.

Correlation between the factors of the revised and the original dimension

\begin{tabular}{lccccc}
\hline & 1 & 2 & 3 & 4 & 5 \\
\hline 1. Vulnerability & 1 & & & & \\
2. Anxious Concern & $0.49^{* *}$ & 1 & & & \\
3. Hopelessness & $0.35^{* *}$ & $0.26^{* *}$ & 1 & & \\
4. Original Instability & $0.91^{* *}$ & $0.61^{* *}$ & $0.45^{* *}$ & 1 & 1 \\
5. Instability Revised & $0.84^{* *}$ & $0.86^{* *}$ & $0.53^{* *}$ & $0.87^{* *}$ & \\
\hline
\end{tabular}

${ }^{* *} p<=0.01$.

Table 5.

Correlation between the total score, factors and dimensions, and Neuroticism facets of the NEO-PI-R

\begin{tabular}{lccccccc}
\hline & Anx. & Anger & Dep. & Emb. & Imp. & Vul. & Neu. \\
\hline Vulnerability & $0.44^{* *}$ & $0.58^{* *}$ & $0.53^{* *}$ & $0.32^{* *}$ & $0.45^{* *}$ & $0.46^{* *}$ & $0.60^{* *}$ \\
Anxious Concern & $0.46^{* *}$ & $0.41^{* *}$ & $0.55^{* *}$ & $0.40^{* *}$ & $0.35^{* *}$ & $0.37^{* *}$ & $0.55^{* *}$ \\
Hopelessness & $0.30^{* *}$ & $0.27^{* *}$ & $0.29^{* *}$ & $0.17^{*}$ & $0.13^{*}$ & $0.40^{* *}$ & $0.34^{* *}$ \\
Original Instability & $0.52^{* *}$ & $0.66^{* *}$ & $0.61^{* *}$ & $0.40^{* *}$ & $0.50^{* *}$ & $0.57^{* *}$ & $0.70^{* *}$ \\
Revised Instability & $0.55^{* *}$ & $0.58^{* *}$ & $0.62^{* *}$ & $0.39^{* *}$ & $0.41^{* *}$ & $0.50^{* *}$ & $0.66^{* *}$ \\
\hline
\end{tabular}

Note. Ans.=Anxiety; Dep.=Depression; Emb.=Shame/Embarrassment; Imp.=Impulsiveness; Vul.=Vulnerability; Neu.=Neuroticism. ${ }^{*} p<=0.05 .{ }^{* *} p<=0.01$.

It is worth noting that the measurements for the total score of the original dimension of the NEO-PI-R ranged between 0.40 and 0.70 , and magnitudes for the total score of the revised dimension with the facets ranged between 0.39 and 0.66 , suggesting larger measurements with the revised dimension. Regarding DCPI factors and Neuroticism facets, most correlations were low or moderate with the NEO-PI-R facets and all positive. The Hopelessness factor presented the lowest correlations. In relation to the Vulnerability factor, the highest correlation was with Anger; Anxious concern had the highest correlation with Depression; and the Hopelessness factor showed the highest correlation with the Vulnerability facet. Table 6 shows the correlations of the factors and the total score of the revised dimension with the facets of the Agreeableness dimension of NEO-PI-R.
Table 6 shows that most of the correlations of the factors and the total score, both in the revised dimension and the original, presented negative values with the facets of Agreeableness (NEO-PI-R) and were clearly lower in relation to the measurements with Neuroticism. The total score of the revised dimension had lower correlations in all facets compared to the original, except for Sensitivity, which presented the same value. As to the factors of the revised dimension, Vulnerability presented a higher measurement with Complacency; Anxious Concern obtained only low correlations, near zero; and, the Hopelessness factor showed a higher magnitude with the Trust facet. Table 7 shows the correlations of the revised dimension and the five facets of PID-5.

Table 6.

Correlations between the total score, factors, and dimensions and facets of the Agreeableness domain-NEO-PI-R

\begin{tabular}{lccccccc}
\hline & Con. & Str. & Alt. & Com. & Mod. & Sen. & Agr. \\
\hline Vulnerability & $-0.35^{* *}$ & $-0.15^{*}$ & $-0.19^{* *}$ & $-0.43^{* *}$ & -0.07 & $-0.23^{* *}$ & $-0.37^{* *}$ \\
Anxious Concern & $-0.15^{*}$ & 0.01 & 0.01 & $-0.23^{* *}$ & 0.07 & -0.05 & -0.10 \\
Hopelessness & $-0.21^{* *}$ & $-0.18^{* *}$ & -0.13 & -0.13 & -0.03 & -0.12 & $-0.20^{* *}$ \\
Original Instability & $-0.36^{* *}$ & $-0.14^{*}$ & $-0.24 * *$ & $-0.43^{* *}$ & -0.03 & $-0.18^{* *}$ & $-0.36^{* *}$ \\
Instability Revised & $-0.29^{* *}$ & -0.08 & -0.13 & $-0.38^{* *}$ & 0.01 & $-0.18^{* *}$ & $-0.28^{* *}$ \\
\hline
\end{tabular}

Nota. T.=Trust; Str.=Straightforwardness; Alt.=Altruism; Com.=Compliance; Mod.=Modesty; Sen.=Sensitiveness; Agr.=Agreeableness. ${ }^{*} p<=0.05 .{ }^{* *} p<=0.01$. 
Table 7.

Correlations between Mood Instability and PID-5 facets

\begin{tabular}{lccccc}
\hline & Anx. & Dep. & Lab. & Ins. & Imp. \\
\hline Vulnerability & $0.54^{* *}$ & $0.48^{* *}$ & $0.62^{* *}$ & $0.38^{* *}$ & $0.54^{* *}$ \\
Anxious Concern & $0.61^{* *}$ & $0.43^{* *}$ & $0.49^{* *}$ & $0.57^{* *}$ & $0.38^{* *}$ \\
Hopelessness & $0.34^{* *}$ & $0.68^{* *}$ & $0.26^{* *}$ & $0.37^{* *}$ & $0.18^{* *}$ \\
Original Instability & $0.61^{* *}$ & $0.59^{* *}$ & $0.64^{* *}$ & $0.47^{* *}$ & $0.62^{* *}$ \\
Instability Revised & $0.67^{* *}$ & $0.61^{* *}$ & $0.62^{* *}$ & $0.56^{* *}$ & $0.53^{* *}$ \\
\hline
\end{tabular}

Note: Anx.=Anxiety; Dep.=Depressiveness; Lab.= emotional lability; Ins.=Separation Insecurity; Imp.=Impulsiveness. ${ }^{* *} p<=0.01$.

It is observed that the DCPI correlations with the PID5 were significantly higher than the correlations with the dimensions and facets of the NEO-R-PI, most of them of moderate magnitude. Furthermore, Table 7 shows that some of the correlations of the total score of the revised dimension were higher compared to the original, but still, they were all similar. In relation to the factors of the new dimension, Vulnerability showed a higher correlation with Emotional Lability; Anxious Concern with Anxiety and Insecurity; and Hopelessness obtained a higher correlation with Depressiveness.

\section{DISCUSSION}

This study aimed to review the Mood Instability dimension of the DCPI and to verify its psychometric properties. The Mood Instability dimension of the DCPI originally covers the evaluation of characteristics such as sad and irritable mood, widespread instability, extreme oscillations (dysregulation) in mood and beliefs, manifested in impulsive reactions, which mostly generate guilt and may result in suicide (Carvalho \& Primi, 2015; in press). According to the study by Abela (2013), this dimension is the most relevant for the borderline PD, which is expected, considering the characteristics of the underlying disorder (APA, 2013) and the dimension. The starting point was the creation of 306 items, of which 27 were selected for application including the constructs Concern, Depressiveness, Impulsivity, Separation Avoidance, Disorientation, and Emotional Intensity, enhancing their representativeness in the revised dimension. It is noteworthy that the new selected items were applied along with the original items of the dimension.

The Mood Instability dimension revised, after psychometric analysis, comprises 16 items, including six original and 10 new items. It was sought to explicitly keep a limited number of items per factor, and in the overall dimension, enabling the use of the DCPI dimensions in the clinical setting, but still maintaining the representativeness of the evaluated constructs. These items were divided into three factors, named as Vulnerability (six items), Anxious Concern (six items) and Hopelessness (four items), with adequate internal consistency coefficients (Embretson, 1996; Nunnally, 1978). The total score of the revised dimension also had adequate internal consistency, 0.85 , which is a coefficient close to that found by Carvalho and Primi (2015), 0.94 , especially considering that the revised dimension has approximately $40 \%$ fewer items compared to the original.

In the first factor, Vulnerability items related to mood instability, impulsivity leading to feelings of guilt, and tendency towards loss of control that could lead to injury, exemplified by the item "My mood changes from one extreme to another very easily" were grouped together. It is observed that the vulnerability factor expresses elements of the central functioning typical of the Neuroticism dimension (Costa Jr. \& McCrae, 2009) and, especially, the borderline PD (APA, 2013). The next factor, Anxious Concern, refers to anxiety and intense concern for future events, as well as fear of being alone, such as in the item "I am very worried about the terrible things that can happen". Finally, the Hopelessness factor involves feelings of sadness, despair, and suicidal thoughts, exemplified in the item "I know there's nothing I can do to improve my future." It is expected that the distribution of the Mood Instability dimension into three factors consistent with the overall dimension will be more informative from the practical standpoint only with respect to the total score, as was the case of the original dimension. Additionally, from the references presently used to create new items, it appears that the representation of the construct accessed by the Mood Instability dimension has been expanded. These elements should be examined in future studies. It is important to highlight that there was not a particular number of factors previously expected, but the groups of items found are consistent with the literature (Clark, 1990; Krueger et al., 2011; Shedler \& Westen, 2004) 
and in relation to the patterns typically characterized by mood instability, such as the borderline PD (APA, 2013). In this sense, the present findings suggest evidence of validity based on the internal structure for the revised scale.

Besides this, it was found that most of the intracorrelations of the factors in the revised dimension were low and moderate, suggesting the possibility of obtaining personality profiles for people assessed by the Mood Instability dimension. On the other hand, the internal consistency observed for the total score also indicates the cohesion among the factors composing the Mood Instability revised dimension. These data suggest that individuals with similar scores in the dimension overall score should have sometimes different scores on the factors that make it up, enabling a detailed differentiation between these people.

With respect to the correlations between the factors with the original dimension, we observed lower magnitudes with Hopelessness followed by the factor Anxious concern, indicating that the new dimension encompasses these characteristics that were underrepresented before. Regarding the Vulnerability factor, the correlation was high suggesting that this construct was already encompassed in the original dimension. Furthermore, the value of the correlation between the total scores of the original and the revised versions was high, indicating a common underlying construct between them.

Regarding the correlations of the DCPI with other applied instruments, the Neuroticism dimension was considered for the NEO-PI-R, whose definition is similar to that of the Mood Instability dimension; besides, the literature on both dimensions indicates that they are related to the borderline functioning (Abela, 2013; Mullins-Sweatt et. al., 2012.). The Agreeableness dimension was also analyzed because it evaluates characteristics related to interpersonal relationships, such as confidence, for instance, which are low in borderline individuals (McCrae \& Costa Jr., 2009).

The Neuroticism dimension had a higher correlation with the original dimension, except for the facets Anxiety and Depression. Considering that the NEO-PI-R was developed to assess healthy personality characteristics (Costa $\& \mathrm{McCrae}, \mathrm{Jr} ., 2009)$, although the Neuroticism dimension is an exception to this, it is possible that even the items referring to more dysfunctional characteristics do not access more severe levels of functioning. This hypothesis, which was raised due to the observed data, but also based on the development of NEO-PI-R and the five-factor model, is also confirmed by the correlations found between the DCPI and the PID-5, discussed in subsequent paragraphs. The facets of Neuroticism which obtained the highest correlation with the total score of the revised scale were depression and anger, which is consistent, given that the Mood Instability dimension of the DCPI should be more related to the characteristics of borderline functioning (Carvalho \& Primi, 2015), as is the case of depressiveness and irritability (APA, 2013). Moreover, it is observed that the correlations were moderate with all facets of Neuroticism, indicating that the Mood Instability factors assess characteristics such as anxiety, depressiveness, irritability and impulsivity, as it is expected given its evaluative purpose. It is noteworthy, too, that the highest correlation of Anxious Concern was with Depression and not with Anxiety (NEO-PI-R), which should be examined in depth in future studies, since it does not corroborate what was conceptually expected. Still, it should be noted that this factor of the Mood Instability dimension presented coherent correlation with the PID-five facets, such as observed on the data.

Regarding the Agreeableness dimension, correlations were mostly negative and significantly lower when compared to those presented with Neuroticism. On the one hand, negative magnitudes were expected, as they indicate that the greater the number of characteristics on the Mood Instability dimension, the greater the tendency to present difficulties and losses in interpersonal relationships (Costa Jr. \& McCrae, 2009), suggesting the tendency of the DCPI's dimension to assess more pathological than healthy patterns. On the other hand, it should be pointed out that this dimension of NEO-PI-R does not show facets respectively correlated to the factors of the revised dimension of the DCPI, which may explain the low correlations. Moreover, we observed that of the five dimensions of the Big Five factor model, only Neuroticism includes facets that may be more directly related to the underlying characteristics of DCPI's Mood Instability. Nevertheless, the expected relationship between the DCPI dimension and Agreeableness facets was found, which is a favorable validity evidence for the revised scale.

Finally, it was observed that the correlations between the DCPI and the PID-5 were more significant than those found for the NEO-PI-R, and the revised dimension obtained higher correlations compared to the original, except for two facets: emotional lability and impulsivity. It is noteworthy that the original dimension Mood Instability, unlike Conscientiousness and Attention Seeking (see Carvalho et al, 2014; Carvalho, Souza et al., 2014) did not present data suggesting a need for developing items that were even more pathological for this dimension, which should explain the similar magnitudes between the revised and the original total scores with PID-5. Thus, these data indicate that both the PID-5 and the DCPI assess the more pathological functioning of personality, which was expected, and also provides evidence of validity to the dimension of the DCPI. Also, possibly by evaluating close ranges in terms of severity, the correlations between the facets and factors of 
such instruments were more consistent than those found between the DCPI and the NEO-PI-R.

The DCPI's Vulnerability factor presented a higher correlation score with Emotional lability, which is consistent, since these two groups of items relate to the evident mood fluctuation and tendency to vulnerability (Krueger et al., 2011). However, the measures of Vulnerability with Anxiety and Impulsivity of the PID-5 were also high, indicating that this factor is also related to less weighed and vigilant patterns with future occurrences. Anxious concern related mainly with Anxiety, which is also consistent, as they both deal with excessive concern, especially with bad things that the subject believes will occur in the future; moreover, this factor was also related to Insecurity of Separation (PID5), indicating that this set of items of the Mood Instability dimension also evaluates aspects related to the fear of being abandoned in the future by people who matter, which is also consistent considering that the DCPI's dimension is related to the borderline pattern. Finally, Hopelessness correlated more expressively with Depressiveness, which also gives favorable evidence of validity to the Mood Instability dimension, as both the factor and the facet are related to a tendency towards sad mood and beliefs that their life is bad, and that there is nothing that can be done to improve future prospects.

According to the results presently found it can be said that the aim of the present study was reached, with data that provide evidence of validity to the revised dimension and emphasize the adequacy of internal consistency coefficients. In addition, the dimension was further enhanced with the possibility to check different profiles composed from groups of items of Mood Instability, and the increase in the representation construct evaluated by the Mood Instability dimension.

In addition to the theoretical relevance of the groups found that compose the revised dimension, the correlations also highlight the adequacy of the dimension, especially those with the PID-5. Nevertheless, this research consists on an initial study aimed at refining one of the dimensions of the DCPI, and therefore, further research remains to be conducted with this dimension. It is suggested that further studies should examine the following topics more in depth: the functioning of the dimension in psychiatric patients, especially in those diagnosed with borderline $\mathrm{PD}$, the possible profiles that may be found with Mood Instability factors, including the general population; the correlation between anxious concern (DCPI) and depression (NEO-PI-R), here observed, besides analyses of the DCPI's dimension with all dimensions and the facets of the NEO-PI-R. Indeed, the absence of a group of patients with psychiatric diagnosis is a limitation that should be considered while analyzing the present results. Firstly, significant changes in the pattern of correlations here evidenced are not expected in samples presenting more pathological traits (for instance, composed of psychiatric patients), since it is understood that all individuals present the traits measured at some level. On the other hand, the increase in variability and agreement of the instruments used on the Likert-type scale may present a change in the obtained results and, therefore, future studies should investigate the possible replicability of the data found here.

We also observed that the use of mathematical models exploring the functioning of the revised dimension at the item level (e.g., rating scale model) should be of great value. It is also important that future research deal with the limitations of this study, including a small sized sample and a non-clinical sample.

\section{REFERENCES}

Abela, R. K. (2013). Evidências de validade para o Inventário Dimensional Clínico da Personalidade (IDCP) com base nos perfis de participantes com diagnostico psiquiátrico. Tese de Doutorado-Universidade Federal de São Paulo, São Paulo.

American Psychiatry Association (APA). (2003). Diagnostic and Statistical Manual of Mental Disorders. Fourth Edition Revised. Washington: American Psychiatry Association.

American Psychiatry Association (APA). (2013). Diagnostic and Statistical Manual of Mental Disorders 5. Washington: American Psychiatry Association. Disponível em: $<$ http://www. dsm5.org/Pages/Default.aspx>. Acesso em 10/03/ 2014.

Carvalho, L. F. \& Primi, R. (2015). Development and internal structure investigation of the Dimensional Clinical Personality Inventory. Psicologia: Reflexão e Crítica, 28(2), 322-330.

Carvalho, L. F. \& Primi, R. (no prelo). Prototype matching of personality disorders with the Dimensional Clinical Personality Inventory. Psicologia: Teoria e Pesquisa.

Carvalho, L. F., Primi, R. \& Stone, G. E. (2014). Psychometric properties of the Inventário Dimensional Clínico da Personalidade (IDCPI) using the Rating Scale Model. Avances en Psicología Latinoamericana, 32 (3), 433-446.

Carvalho, L. F., Sette, C. P., Capitão, C. G. \& Primi, R. (2014). Propriedades psicométricas da versão revisada da dimensão necessidade de atenção do inventário dimensional clínico da personalidade. Temas em Psicologia, 22(1), 147-160.

Carvalho, L. F., Souza, B. D. B. \& Primi, R. (2014). Psychometric properties of the revised conscientiousness dimension of Inventário Dimensional Clínico da Personalidade (IDCPI). Revista de Psiquiatria do Rio Grande do Sul, 36, 23-31.

Choca, J. P. (2004). Interpretative guide for the Millon Clinical Multiaxial Inventory III. Washington, DC: American Psychological Association. 
Clark, L. A. (1990). Toward a consensual set of symptom clusters for assessment of personality isorder. In Butcher, J. N. \& Spielberger, C. D. (Orgs.) Advances in personality assessment. New Jersey: Lawrence Erlbaum Associates.

Costa Jr., P. T. \& McCrae, R. R. (2009). NEO-PI-R-Inventário de Personalidade NEO Revisado-Manual. São Paulo: Vetor.

Embretson, S. E. (1996). The new rules of measurement. Psychological Assessment, 8(4), 341-349.

Hayton, J. C., Allen, D. G. \& Scarpello, V. (2004). Factor retention decisions in exploratory factor analysis: A tutorial on parallel analysis. Organizational Research Methods, 7(2), 191-205.

Hooper, D., Coughlan, J. \& Mullen, M. R. (2008). Structural equation modelling: Guidelines for determining Model Fit. The Electronic Journal of Business Research Methods, 6(1), 53-60.

John, O. P., Robins, R. W. \& Pervin, L. A. (2008). Handbook of personality: theory and research. Third edition. New York: The Guilford Press.

Krueger R. F., Derringer J., Markon K. E., Watson D. \& Skodol A. E. (2011). Initial construction of a maladaptive personality trait model and inventory for DSM-5. Psychological Medicine, 8, 1-12.

Leichsenring, F., Leibing, E., Kruse, J., S New, A. \& Leweke, F. (2011). Borderline personality disorder. Lancet, 377, 74-84.

Loureiro, S. R. (2000). Transtornos de Personalidade e avaliação psicodiagnóstica. In Sisto, F. F., Sbardelini, E. T. B. \& Primi, R. (Orgs), Contextos e questões da avaliação psicológica (pp. 51-61) São Paulo: Casa do Psicólogo.

Millon, T. (1993). Personality Disorders: Conceptual distinctions and classification issues. In P. T. Costa \& T. A. Widiger, Personality Disorders and the Five-Factor Model of Personality. Washington, DC: American Psychiatry Association.

Millon, T. (2011). Disorders of Personality: introducing a DSM/ ICD spectrum from normal to abnormal. New Jersey: Wiley.

Millon, T. \& Davis, R. D. (1996). Disorders of personality DSMIV and beyond. New Jersey: Wiley.

Millon, T. \& Davis, R. D. (1997). The MCMI-III: Present and future directions. Journal of Personality Assessment, 68(1), 69-85.

Millon, T., Millon, C. M., Meagher, S., Grossman, S. \& Ramanath, R.. Personality disorders in modern Life. New Jersey: Wiley.
Millon, T. \& Grossman, S. (2007a). Moderating severe personality disorders. New Jersey: John Wiley \& Sons Inc.

Millon, T. \& Grossman, S. (2007b). Overcoming resistant personality disorders. New Jersey: John Wiley \& Sons Inc.

Millon, T., Grossman, S. \& Tringone, R. (2010). The Millon personality spectrometer: a tool for personality spectrum analyses, diagnoses, and treatments. In Millon, T. (Org.), Disorders of Personality: introducing a DSM/ICD spectrum from normal to abnormal. New Jersey: Wiley.

Mullins-Sweatt, S. N., Edmundson, M., Sauer-Zavala, S., Lynam, D. R., Miller. J. D. \& Widiger, T. A. (2012). Five-factor measure of borderline personality traits. Journal of Personality Assessment, 94(5), 475-487.

Nunnally, J. C. (1978). Psychometric theory. New York: McGrawHill.

Samuel, D. B. \& Widiger, T. A. (2004). Clinicians' personality descriptions of prototypic personality disorders. Journal of Personality Disorders, 18, 286-308.

Shedler, J. \& Westen, D. (2004). Dimensions of personality pathology: An alternative to the five factor model. American Journal of Psychiatry, 161, 1743-1754.

Skodol, A. E., Clark, L. A., Bender, D. S., Krueger, R. F., Morey, L. C., Verheul, R., Alarcon, R. D., Bell, C. C., Siever, L. J. \& Oldham, J. M. (2011). Proposed changes in personality and personality disorder assessment and diagnosis for DSM-5 Part I: Description and rationale. Personality disorders: theory, research, and treatment, 2(1), 4-22.

Strack, S. \& Millon, T. (2007). Contributions to the dimensional assessment of personality disorders using Millon's model and the Millon Clinical Multiaxial Inventory (MCMI9-III). Journal of Personality Assessment, 89(1), 56-69.

Watkins, M. W. (2006). Determining parallel analysis criteria. Journal of Modern Applied Statistical Methods, 5(2), 344-346.

Westen, D. \& Shedler, J. (1999). Revising and assessing Axis II, Part I: Developing a clinically and empirically valid assessment method. American Journal of Psychiatry, 156, 258-272.

Widiger, T. A. \& Trull, T. J. (2007). Place tectonics in the classification of personality disorder: shifting to a dimensional model. American Psychologist, 62(2), 71-83. 